\title{
The Influence of Shared Leadership on Employees' Knowledge Sharing Behavior
}

\author{
Dian Zhang ${ }^{1, \mathrm{a}}$
}

\author{
${ }^{1}$ Hong Kong Shue Yan University \\ a183018@hksyu.edu.hk
}

\begin{abstract}
Individual knowledge sharing behavior is one of the most basic links in the process of knowledge management. How to make employees generate the willingness to share knowledge is more important than the transfer, storage and utilization of knowledge. Knowledge sharing behaviors arise from the willingness to share. Leadership style is one of the organizational context factors. Different types of leadership styles have differences in individual knowledge sharing behaviors. In a specific situation, based on the theoretical basis of shared leadership, the relationship between knowledge sharing motivation and shared behavior, and through case analysis, it proves the impact of shared leadership on employees' knowledge sharing behavior. The results show that shared leadership has a non-negligible influence on knowledge sharing motivation and knowledge sharing behavior.
\end{abstract}

Keywords: Shared leadership, Shared motivation, Sharing behavior, Innovation.

\section{INTRODUCTION}

Knowledge is not only its core production resource, but also the key to enterprise innovation. Active knowledge sharing behavior among enterprises can help accelerate enterprise innovation, thereby enhancing the competitiveness of enterprises. This article intends to conduct an empirical study on the motivation and behavior of knowledge sharing by shared leadership from the individual level. Research and innovation to explore shared leadership has an inseparable influence on knowledge sharing motivation and knowledge sharing behavior. The research on the relationship between knowledge motivation and knowledge sharing behavior is based on theoretical exploration and inference. Limitations of the research. For the measurement of knowledge sharing behavior, this research draws on the scales developed by previous people but does not conduct detailed research on knowledge sharing behavior. It is hoped that future research can refine the categories of knowledge sharing and conduct deeper research. Knowledge sharing behavior and knowledge sharing motivation are a very complicated process, and there are many motivations for sharing behavior.

\section{REVIEW OF LITERATURE}

\subsection{Shared leadership}

The role of leadership is assumed by multiple individuals in the group, rather than the authority of a single individual. Multiple individuals assume leadership roles to achieve collective decision-making functions and goals and tasks within groups and organizations. This collective leadership model is called for shared leadership. Organizational research scholars emphasize that shared leadership (the leadership role is shared by a group of people) is an effective leadership style when members are highly interdependent, creativity is the core requirement, and task complexity is high. [2][8]. Therefore, shared leadership is a dynamic process of selecting individuals with expertise in completing the tasks as leaders according to the established tasks of the team or organization and achieving the common goals of the organization through the transformation and dynamics of the leaders' functions.

\subsection{Knowledge sharing motivation}

There is a mutual exchange mechanism between individuals and groups. The motivation is the individual's willingness to take a certain behavior under the influence of self-regulation to realize a certain demand. Knowledge 
sharing motivation is the individual's willingness to take the initiative to share knowledge with others in order to achieve the set goals and realize their own needs [7]. Moreover, under the inducement of certain rewards and benefits, the willingness of individuals to actively exchange knowledge with others has become the driving force for knowledge sharing.

\subsection{Knowledge sharing behavior}

The behavior of individuals in a team or organization to exchange their own explicit knowledge and tacit knowledge is knowledge sharing within the organization. After acquiring knowledge, individuals and other individuals jointly innovate knowledge and stimulate their own innovative behavior. [6] The premise of knowledge sharing is the willingness of the sharing parties to share. The subject of knowledge diffusion rises from the individual level to the organizational level. This process is called knowledge sharing. Therefore, the knowledge sharing behavior is the behavior generated by the needs of the knowledge holder and the knowledge demander to realize the work required by the experience, skills, and experience.

\section{RESEARCH HYPOTHESIS}

There is a relationship between knowledge sharing motivation and knowledge sharing behavior

In the theory of social exchange, the knowledge sharing behavior of employees depends on whether the individual can obtain corresponding rewards in the process of knowledge sharing. Moreover, after the individual meets the physiological needs, social recognition and respect are the higher-level needs of employees, and they are important factors for the consideration of employee knowledge sharing. In order to satisfy social interaction and maintain a certain colleague relationship, employees will increase the possibility of consensus sharing.

\subsection{The Influence of Shared Leadership on Knowledge Sharing Motivation}

The main dimensions of shared leadership are focus on team goals, performance expectations, cooperation to support sharing of powers and responsibilities, and personalized care. However, economic remuneration is an external requirement for employee knowledge sharing; The sharing of power and responsibility emphasizes that personal interests and the team are an organic whole. Shared leadership through team learning, knowledge exchange and sharing between team members, helps employees establish an expert image and gain the recognition and respect of other members. The selfindependence of employees is based on the needs of selfdevelopment, not limited to completing the existing tasks of the team, but also including promoting other team members to complete the set goals and gaining prestige and self-efficacy in the organization by completing their own tasks and helping others to take organizational behaviors.

\subsection{Shared leadership influences knowledge sharing motivation and knowledge sharing behavior}

The knowledge sharing behavior of employees originates from the willingness to share knowledge. The traditionality of employees is reflected in their obedience to authoritative leadership.

Performance expectation is an employee's expected psychological state after completing a given job. Work performance is closely related to the employee's economic benefits. In the theory of economic transactions, employees obtain corresponding rewards and rewards by sharing knowledge. Economic rewards and material rewards are important basis for the analysis of employee benefit costs. Non-material remuneration includes employees' psychological perception, sense of accomplishment, prestige and status. Therefore, the employee's performance expectation has an impact on the individual's knowledge sharing behavior through knowledge sharing motivation and intermediary effects.

\section{EMPIRICAL ANALYSIS}

There is a relationship between knowledge sharing motivation and knowledge sharing behavior

\subsection{Economic motivation-organizational compensation}

In economic exchange theory and knowledge market theory, individual behavior is guided by self-interest, and the motivation of individual knowledge sharing behavior is reflected in the fact that the economic benefits obtained are greater than the cost of the behavior. Driven by extrinsic motivation, individuals will only adopt knowledge sharing behaviors when they expect a certain behavior to obtain equivalent or super-value returns. For knowledge itself, knowledge sharing will not make it disappear, but sharing knowledge will increase the value of knowledge. But for knowledge holders, knowledge is, after all, a competitive resource. When knowledge holders are required to have their own exclusive knowledge to share with others, they will inevitably worry that their social status will be shaken. The most direct result is the loss of the organization's right to speak, and the loss of opportunities for promotion and salary increase. 


\subsection{Communication motivation-reciprocity}

Communication motivation refers to the individual's willingness to belong to a certain group, like to interact with others, and hope to get the care, friendship, support, cooperation and appreciation of others. Under the influence of communication motivation, the purpose of employees sharing knowledge is to expect future reciprocity and gain the recognition of others. [5] Davenport and Prusak believe that individuals will share knowledge under three conditions, including mutual benefit. Reciprocity: It means that the seller of knowledge expects that the buyer of knowledge will provide the same help in the future to meet his needs for knowledge sharing. [3] Research shows that reciprocity is a significant motivation for knowledge sharing in a database of casual communication. Bock \& Kim 2002 also emphasized the importance of reciprocity in a knowledge sharing environment. Empirical research found that Expected Associations (EA) has a significant impact on knowledge sharing behaviors and attitudes [1]. Individuals will continue to cooperate with each other and share knowledge with others only when they find exchange relationship attractive (some useful information and knowledge can be obtained from the other party).

\subsection{Motivation from achievement-self-growth}

Hendriks (1999) explored the factors that affect personal knowledge sharing motivation based on the twofactor theory [4]. The study found that the reasons why people share knowledge tend to be motivational factors rather than health care factors. Motivating factors include work achievement, achievement recognition, work challenge and fun, sense of responsibility, development and growth. Through mutual learning to obtain opportunities for learning and growth, these satisfactions from within the individual help to mobilize the enthusiasm of individuals for sharing. According to the Maslow theory, Stott \& Walker (1995) pointed out that knowledge workers are unwilling to share knowledge for money or to improve the relationship between colleagues. The motivation for knowledge sharing mainly comes from the three higher levels of belonging, self-esteem, and self-realization [9]. Self-realization needs affect employees' motivation for knowledge sharing. He also believes that the growth of personal career development affects employees the most. These intangible or tangible incentives will all affect employees' motivation for knowledge sharing.

\subsection{The Influence of Shared Leadership on Knowledge Sharing Motivation}

When team members solve complex problems, they not only rely on their own knowledge, but also seek external knowledge support from other members, thus becoming knowledge demanders. The demanders of knowledge usually need insights, judgments and understanding of things from outside. Correspondingly, knowledge can flow between the provider and the demander of knowledge, through the selective "push" and "pull" of knowledge. " The team can complete tasks efficiently mainly because its members can share valuable and scarce knowledge resources to form team capabilities to improve work performance and create value. Therefore, team members play the dual roles of knowledge supply and demand each other. This two-way "push" and "pull" process between team members is the micro-mechanism of knowledge sharing, and the key driving element of this micro-mechanism is team leadership.

\subsection{Shared leadership influences knowledge sharing motivation and knowledge sharing behavior}

Shared leadership is a unique and effective way of leadership, which is motivated by vision and belief, and is a way of leadership that employees have a sense of mission and identity to gain a sense of spiritual presence. Shared leadership will stimulate employees' enthusiasm for work with their own values, attitudes and behaviors, and have a positive impact on their behavior. Individual sharing motivation is an important pre-variable for sharing behavior. For software company employees, their sharing motives and sharing behaviors will vary according to whether the company is motivated or not. Knowledge sharing motivation and knowledge sharing behavior are inseparable from shared leadership, and shared leadership has a greater impact.

\section{CONCLUSION}

Through theoretical research and empirical analysis of shared leadership and employee knowledge sharing behavior, shared leadership and employee knowledge are inextricably linked. There are some feasible suggestions for this, on the one hand, increase organizational commitment, reduce power distance. Shared leadership is a dynamic leadership method for collective decisionmaking, highlighting employees' participation in organizational decision-making, and enhancing employees' sense of belonging to the organization. On the other hand, it enriches existing incentive mechanisms. Motivations for knowledge sharing are mainly divided into material rewards and non-material rewards. Employees produce knowledge sharing behaviors under internal demand and external incentives and expect to receive corresponding rewards from the organization. Managers should improve the organization's salary system and welfare measures to stimulate and promote knowledge sharing among employees. This is also the most direct influence of shared leadership on knowledge sharing motivation and knowledge sharing behavior. 


\section{REFERENCES}

[1] Bock, G. W. Kim Y. G. Breaking the myths of rewards: Anexploratory study of attitudes about knowledge sharing [J]. Information Resource Management Journal, 2002, 15(2) : 14-213

[2] Connolly T, Thorn B. K. Discretionary Databases: Theory, Date, andImplications[M]. Newbury Park, CA: Sage Publications, 1990: 219-233

[3] Davenpor T, Prusak L. Working Knowledge[M]. Harvard Business School Press,Cambridge, MA, 1998

[4] Hendriks, P. Why Share Knowledge? The Influence of ICT on Motivation for

[5] Huang, C.-- H. (2013). Shared leadership and team learning: Roles of knowledge sharing and team characteristics. Journal of International Management Studies, 8(1), 124-133.

[6] Knowledge Sharing [J]. Knowledge and Process Management, 1999, 6(2) :91-100[8] Hidding, G. \& Shireen M. C. Anatomy of a learning organization: Turning knowledge into capital capital at Andersen Consulting" [J] Knowledge and Process Management, 1998, 5(1):3-13

[7] Kozlowski, S. W., Gully, S. M., Salas, E., \& CannonBowers, J. A. (1996). Team leadership and development: Theory, principles, and guidelines for training leaders and teams. In M. M. Beyerlein, D. A. Johnson, \& S. T. Beyerlein (Eds.), Advances in interdisciplinary studies of work teams: Team leadership (pp. 253-291). Elsevier Science/JAI Press.

[8] Pearce, C. L., \& Sims, H. P., Jr (2002). Vertical versus shared leadership as predictors of the effectiveness of change management teams: An examination of aversive, directive, transactional, transformational, and empowering leader behaviors. Group Dynamics: Theory, Research, and Practice, 6(2), 172-198.

[9] Scott, J. W. Facilitating inter organizational learning with information technology $[\mathrm{J}]$. Journal of Management Information Systems, 2000, 17(2): 81113. 